\title{
Current status of iodine deficiency-related disorders prophylaxis in Slovakia - the life's work of Julian Podoba remained unfinished
}

\author{
${ }^{1}$ Podoba J, ${ }^{2}$ Racova K, ${ }^{3}$ Urbankova H, ${ }^{4}$ Srbecky M \\ ${ }^{1}$ Department of Endocrinology, Medical Faculty, Slovak Medical University \\ and St. Elizabeth Cancer Institute, Bratislava,Slovakia; \\ ${ }^{2}$ Institute of Laboratory Medicine, St. Elizabeth Cancer Institute, Bratislava, Slovakia; \\ ${ }^{3}$ National Institute of Endocrinology and Diabetology, Lubochna, Slovakia; \\ ${ }^{4}$ Earth Science Institute, Slovak Academy of Sciences, Bratislava, Slovakia \\ E-mail:podoba.jmz@stonline.sk
}

Objective. Prophylaxis of iodine deficiency-related disorders with iodized salt in Slovakia was introduced in 1951. This prophylactic measure yielded remarkably good results. Endemic goiter and endemic cretinism disappeared. Sufficient iodine intake, mainly in children and adolescents, was confirmed in several local and international studies carried out in the period 1991-95. Unfortunately, since seventies, there has been no institution which would have dealt with iodine prophylaxis in such an extent as this important measure of Slovak preventive medicine would require. Neither systematic monitoring of iodine intake nor systematic population epidemiological studies have been carried out. We do not have any data on the iodine intake in pregnant women, the most vulnerable population group in relation to the iodine deficiency. During the period June 2014 October 2015, we examined iodine excretion in 426 probands from three regions of Slovakia with an emphasis on the pregnant women.

Results. Iodine intake was found to be sufficient, even more than adequate, in all age groups of Slovak population. The only population group with iodine intake borderline or very mild iodine deficiency are pregnant women.

Conclusions: 1/ Iodine nutrition in Slovakia is generally sufficient, even oversteps the requirement, with the exception of pregnant women. Iodine intake in pregnant women should be fortified by iodine containing multivitamin preparations. 2 / We recommend to include the examination of urinary iodine into the screening of thyropathies in early pregnancy. 3/ It is not enough to implement the iodine deficiency-related disorders prevention programs, it is also necessary to stabilize such programs over time and balance the benefits with possible side effects of this program.

Key words: iodine deficiency-related disorders, iodine, prophylaxis, monitoring, side-effects 
Iodine deficiency (ID) has multiple adverse effects on the growth and development in animals and humans. These negative effects are collectively termed as the iodine deficiency-related disorders (IDD) and belong to the most important and common human diseases worldwide. They result from an inadequate thyroid hormone production, due to lack of sufficient iodine intake. ID during pregnancy impairs the neurological development of the fetus. In areas of severe chronic iodine deficiency, maternal and fetal hypothyroxinemia can occur from early pregnancy onwards. Thyroid hormones are required for normal neuronal migration and myelination of the brain during the fetal and early postnatal life. Hypothyroxinemia during these critical periods causes irreversible brain damage, with mental retardation and neurological abnormalities (Morreale de Escobar 2004). The most severe manifestation of intrauterine ID is cretinism.

The main clinical sign of iodine deficiency in affected population is endemic goiter (EG), an adaptive disease which develops when the amount of iodine required for thyroidal metabolism is insufficient. Adaptive processes are triggered and controlled by increased thyroid-stimulating hormone (TSH) stimulation. The consequence of the prolonged thyrotropin stimulation is the development of goiter, the main clinical marker of ID. Adequate secretion of thyroid hormones may still be achieved in spite of low or even very low iodine intake. During pregnancy, a period of increased demands on thyroid function, adaptive mechanisms may fail. Maternal and fetal hypothyroxinemia may result in a detrimental brain damage (Ermans 1980).

People living in areas affected by severe iodine deficiency may have an intelligence quotient (IQ) lower by more than 13.5 points of those from the comparable region communities without iodine deficiency. This mental deficiency has an immediate effect on the child learning capacity, women's health, the quality of life in communities, and economic productivity (WHO 2007).

On the other hand, IDD belong to easiest and cheapest of all the nutrient disorders to be prevented. The adding of a small and constant amount of iodine into the salt that people daily consume, is all what is needed to do. The elimination of IDD is a critical development issue to which the highest priority by governments and international agencies should be given. WHO considers ID to be "the single and most important preventable cause of brain damage“, worldwide (WHO 2007).

In Slovakia, the survey of IDD was carried out by Julian Podoba and coworkers in the period 1949-1953.
They examined 157865 persons (3\% of population) in 602 municipalities. EG affected the population all over the country. In three large and intensively affected regions, $70 \%$ girls, $63 \%$ boys, $80 \%$ adult women, and $46 \%$ adult men suffered from goiter. The occurrence of endemic cretinism was $3 \%$. The iodine excretion in these regions was found to be $\leq 25 \mu \mathrm{g} / 24$ h. In other parts of the country it was $25-50 \mu \mathrm{g} / 24 \mathrm{~h}$ what meant to be severe ID (Podoba 1962).

Prophylaxis of IDD with iodized salt in Slovakia was implemented in 1951. The amount of iodine in salt was carefully increased from $7 \mathrm{mg} \mathrm{KI} / \mathrm{kg}$ to $12 \mathrm{mg} / \mathrm{kg}$ in 1953. Since 1965, common salt has contained $25 \mathrm{mg} \mathrm{KI}$ (18 mg I)/kg; since 2000, more stable $\mathrm{KIO}_{3}$ was added. Since 1966, iodine prophylaxis was compulsory. This prophylaxis measure has yielded remarkably good results. Iodine intake increased 2-4 times, endemic cretinism and EG disappeared, EG remained only in older population (Podoba and Reisenauer 1982).

Increasing standard of living and nutrition in Slovak population raised a question whether the iodine prophylaxis is still needed? In two regions, the distribution of the iodized salt was stopped during the period 1967-73. The iodine excretion decreased to the level found before implementing the iodized salt, i.e. to levels measured 20 years ago. The results of the study showed that in spite of the increasing standard of living in Slovakia, the only guarantor of sufficient iodine intake is the iodine prophylaxis (Podoba and Stukovsky 1972).

Unfortunately, since seventies, the scientific orientation of the Institute of Experimental Endocrinology has significantly changed. The scientific team for IDD has broken up to one or two researchers who could not accomplish this work. Since that time in Slovakia, there was no institution which would have dealt with the iodine prophylaxis to such an extent as this important measure of Slovak preventive medicine would require. Health and political authorities did not take care regarding this problem. Neither systematic monitoring of iodine intake nor systematic epidemiological population studies have been carried out. The follow-up of IDD preventive program has been mostly performed free of charge by volunteers who did this work along with their official work. The iodine content of the table salt has been annually inspected by regional public health offices.

In the period 1985-1995, only a limited number of scientific papers dealing with IDD and its prevention were published. One group of authors, like in Czech Republic, stated that iodine prophylaxis is insufficient and EG grade I in children and adolescents has persisted (Tajtakova et al. 1988, 1989). The other group 
of authors proclaimed the effectiveness of preventive programs in Slovakia. Optimal iodine excretion was confirmed, prevalence of diffuse goiter in adolescents did not meet the criteria of EG and the majority of thyroid enlargements was caused by autoimmune thyroiditis (Podoba jr et al. 1992, 1995).

International study "Standardized evaluation of iodine deficiency in European schoolchildren", carried out under the auspice of WHO, UNICEF, and ICCIDD in 1994/95, confirmed the sufficiency in the iodine intake in schoolchildren in our country. That time Slovakia belonged to five countries with sufficient and highest iodine intake in Europe. Thyroid volumes from Slovakia, the Netherlands and Austria were used to calculate the upper limits of the normal thyroid volume for children and adolescents in Europe (Delange et al. 1997).

UNICEF, ICCIDD, and WHO have recommended the daily intake of iodine: $90 \mu \mathrm{g}$ for preschool children (0 to 59 months); $120 \mu \mathrm{g}$ for schoolchildren (6 to 12 years); $150 \mu \mathrm{g}$ for adolescents (above 12 years) and adults; $250 \mu \mathrm{g}$ for pregnant and lactating women (WHO 2007).

Monitoring of any health intervention is essential to ensure that it is functioning as planned and to provide also information needed to take corrective action if necessary. Therefore, the salt iodization programs require an effective system for monitoring and evaluation. Median urinary iodine concentration (UIC) in morning or other casual urine specimen is the main indicator to be used to assess the iodine status in a population. Additional indicators are palpation and/ or ultrasound goiter assessment, TSH levels in neonates where a screening program is in place, and thyroglobulin in school-age children (WHO 2007).

In children and non-pregnant women, median urinary iodine concentrations (UIC) occurring between $100 \mu \mathrm{g} / \mathrm{l}$ and $299 \mu \mathrm{g} / \mathrm{l}$ define a population without iodine deficiency. In addition, no more than $20 \%$ of samples should be below $50 \mu \mathrm{g} / \mathrm{l}$. Values $100-199 \mu \mathrm{g} / \mathrm{l}$ indicate adequate iodine nutrition, 200-299 $\mu \mathrm{g} / 1$ mean intake above requirement, 55-99 $\mu \mathrm{g} / 1$ signify mild, $20-49 \mu \mathrm{g} / \mathrm{l}$ moderate and $<20 \mu \mathrm{g} / \mathrm{l}$ severe ID. In non-pregnant and non-lactating women, a urinary iodine concentration of $100 \mu \mathrm{g} / \mathrm{l}$ corresponds roughly to a daily iodine intake of about $150 \mu \mathrm{g}$ under steadystate conditions. During pregnancy, median urinary iodine concentrations between $150 \mu \mathrm{g} / \mathrm{l}$ and $249 \mu \mathrm{g} / \mathrm{l}$ define a population without the iodine deficiency, $<150 \mu \mathrm{g} / \mathrm{l}$ indicate insufficient iodine nutrition (WHO 1996, 2007).

Despite the fact that iodine deficiency can easily be prevented by iodine fortifying the salt, Europe belongs to the worst regions in terms of access to the iodized salt. Many European countries did not introduce salt iodization programs, they remained mildto-moderate iodine-deficient, but significant heterogeneity exists in preventing and monitoring IDD programs (Pearce et al. 2013).

A large number of researchers have provided strong evidence that improved iodine status in severely iodine deficient regions eliminated endemic cretinism and impaired neurocognitive function in children in addition to reduction of goiter prevalence. On the other hand, little research has been done in mildly iodine-deficient regions following the implementation of iodized salt prophylaxis. Recent studies have suggested that neurocognitive function in children may be impaired if pregnant women are exposed to even mild ID (Bath et al. 2013; Hynes et al. 2013).

At the beginning of this century, the salt production in Slovakia was brought to an ultimately end. Since that time we have been completely dependent on the imported iodized salt from abroad (mostly Austria). There is an absolute lack of information of the iodine intake in Slovak population, especially of iodine nutrition in pregnant women, the most vulnerable group of population.

The aim of our pilot study was to examine urinary iodine in all age groups of population with the emphasis on the pregnant women.

\section{Subjects and methods}

During the period June 2014 - October 2015, we examined urinary iodine and sodium excretion in 426 volunteers, aged 3-75 years from three regions: south-western Bratislava (bordering with Austria and Hungary), northern Orava, and Liptov regions (bordering with Poland). The characteristics of the study population are shown in Table 1. Pregnant women were divided into two groups: A - taking iodine (multivitamin) preparations (34 women), B not taking iodine preparations (132 women). These multivitamin tablets devoted to pregnant women contained $150 \mu \mathrm{g}$ iodine, in addition to many other vitamins and minerals.

For UI measurement, a rapid quantitative method in microtiter plate format based on Sandell-Kolthoff reaction was used. The method was introduced in the Institute of Laboratory Medicine, St. Elizabeth Cancer Institute in 2009. Median urinary iodine concentration (UIC) is recommended for epidemiological and monitoring studies from various reasons. In spite of this, we preferred the assessment of 24-h urinary iodine excretion $(\mu \mathrm{g} / 24 \mathrm{~h})$ for three reasons: 
1/ 24-h urinary iodine excretion (UIE) can more precisely reflect the individual iodine intake. Using UIC intra-individual variability owing to the hydration status must be considered. 2/ In pregnant women, we wanted to get an exact individual result of iodine nutrition to take immediate measures. 3/ Using UIC, more samples are needed to evaluate epidemiological iodine status. We were not able to examine thousands of urine samples.

\section{Results}

A good correlation was found between 24-h urinary sodium and iodine excretion (Figure 1). It is

Table 1

Study population

\begin{tabular}{lc}
\hline Group & N \\
\hline Children (3-12 years) & 38 \\
Adolescents (13-17 years) & 9 \\
Pregnant women & 166 \\
Women 1 (18-35 years) & 71 \\
Women 2 (36-55 years) & 36 \\
Women 3 (> 55 years) & 33 \\
Men 1 (18-35 years) & 13 \\
Men 2 (36-55 years) & 24 \\
Men 3 (> 55 years) & 36 \\
\hline
\end{tabular}

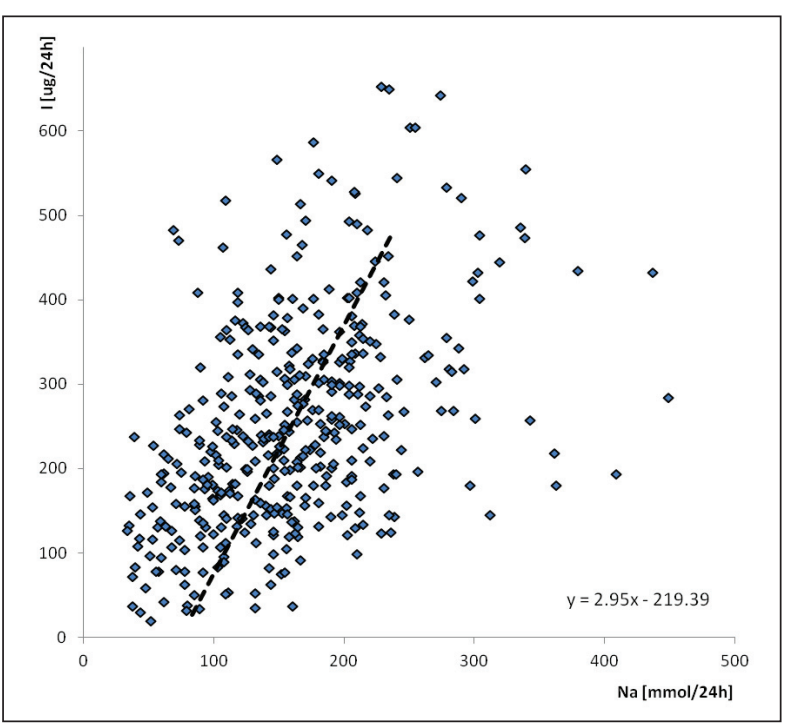

Figure 1. Correlation of 24-h iodine and sodium excretion. clear that iodized salt is the main donor of iodine for Slovakian population, since $90 \%$ of sodium intake comes from $\mathrm{NaCl}$. From 24 -h sodium excretion, the daily intake of table salt could be calculated (Table 2). Sufficient, even more than adequate (above requirement), iodine intake was detected in all age groups of the population (Figure 2). The only group at risk of very mild ID were the pregnant women. Median iodine excretion was $218 \mu \mathrm{g} / 24-\mathrm{h}$. Daily iodine intake in $60 \%$ of them was slightly below the recommended $250 \mu \mathrm{g}$ value. Sufficient iodine nutrition in pregnant women was arranged only with additional multivitamin preparations fortification. Median UIE increased in this group to $320 \mu \mathrm{g} / 24 \mathrm{~h}$ (Figure 3).

\section{Discussion}

Prophylaxis of IDD by iodized salt may not remain effective due to changes in the government policies, commercial factors, and human behavior that may affect the efficacy of the IDD prevention program in unpredictable directions. Monitoring and outcome studies are needed to optimize its effectiveness.

Many events happened in the past in Slovakia with potential harmful impact on the effectiveness of IDD prevention. Since seventies, there has been no institution and no official team in Slovakia which would have dealt with iodine prophylaxis to such an extent as this important measure of Slovak preventive medicine would require. Ten years ago, the table salt production in Slovakia was brought to an ultimately end. Since that time, we have been completely dependent on imported iodized salt from abroad (mostly

Table 2

Median 24-h urinary sodium excretion and calculated salt intake

\begin{tabular}{lcc}
\hline Group & $\begin{array}{c}\mathrm{Na} \\
(\mathbf{m m o l} / \mathbf{2 4} \mathbf{~ h})\end{array}$ & $\begin{array}{c}\mathrm{NaCl} \text { intake } \\
(\mathrm{g})\end{array}$ \\
\hline Children (3-12 years) & 89.0 & 4.6 \\
\hline Adolescents (13-17 years) & 145.5 & 7.5 \\
\hline Pregnant women & 156.0 & 8.1 \\
Women 1 (18-35 years) & 144.0 & 7.5 \\
Women 2 (36-55 years) & 162.5 & 8.4 \\
Women 3 (> 55 years) & 164.0 & 8.4 \\
Men 1 (18-35 years) & 185.0 & 9.7 \\
Men 2 (36-55 years) & 210.0 & 11.0 \\
\hline Men 3 (> 55 years) & 168.0 & 8.5 \\
\hline
\end{tabular}




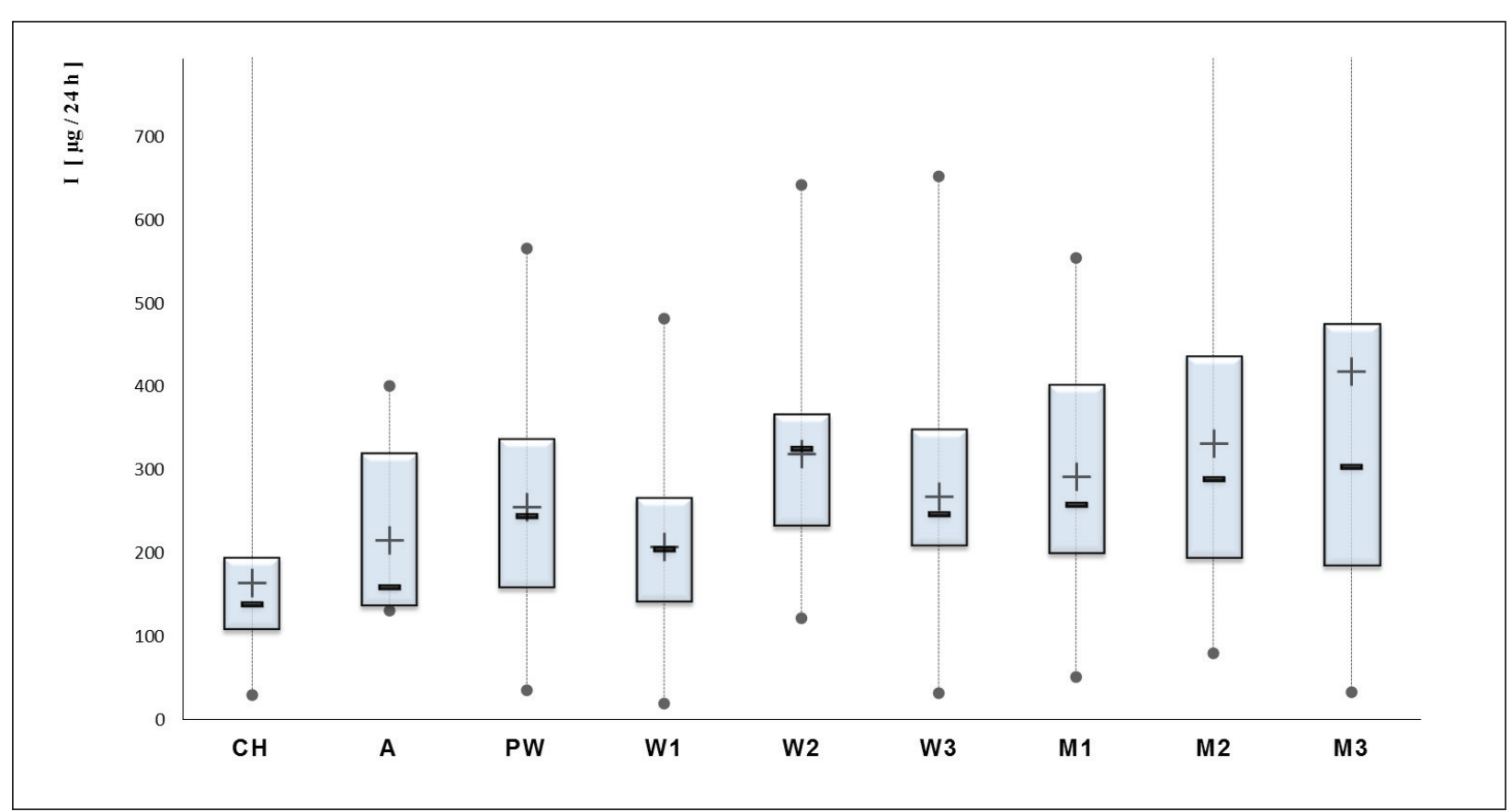

Figure 2. The 24-h urinary iodine excretion in various age groups. Box and whisker plot, - median, + mean

Austria). We could not influence the iodine content in table salt. Due to globalization and free market we cannot influence the amount of sodium that has been added to food during commercial processing or preparation. People are taught do decrease salt consumption. The nutritional habits have changed, especially in young generation. The number of vegetarians has increased, etc.

Fortunately, all these negative events did not influence the iodine nutrition in our country. Iodine content in the table salt has been continuously monitored by regional offices of public health. More than $95 \%$ of imported salt has contained an adequate amount of iodine. The increase of iodine intake compared to eighties is probably caused by salt added to foods during the commercial processing.

We have confirmed an optimal, even more than adequate, iodine nutrition in all age groups of Slovak population. The daily dietary iodine allowance recommended by WHO, UNIEF, and ICCIDD for pregnant and lactating women increased to $250 \mu \mathrm{g}$ in recent past (WHO 2007). To increase daily iodine intake from $150 \mu \mathrm{g}$ before pregnancy to $250 \mu \mathrm{g}$ only by food intake is unreal, possible only in the case of extreme over nutrition. It is not a surprise that $60 \%$ of pregnant women were slightly below $250 \mu \mathrm{g}$. The only way how to reach recommended nutrition is additional fortification of iodine intake by multivitamin preparations containing iodine. Routine prenatal iodine supplementation is recommended by professional bodies in North America (Stagnaro-Green et al. 2011) and Europe (Zimmermann and Delange 2004) but it is unlikely that this is systematically adhered to in many European countries where gestational iodine status remains inadequate. For pregnant women in Slovakia additional $50 \mu \mathrm{g}$ of iodine would be sufficient. When the Slovak population will adopt lower table salt consumption, then the available tablets containing $150 \mu \mathrm{g}$ will be optimal.

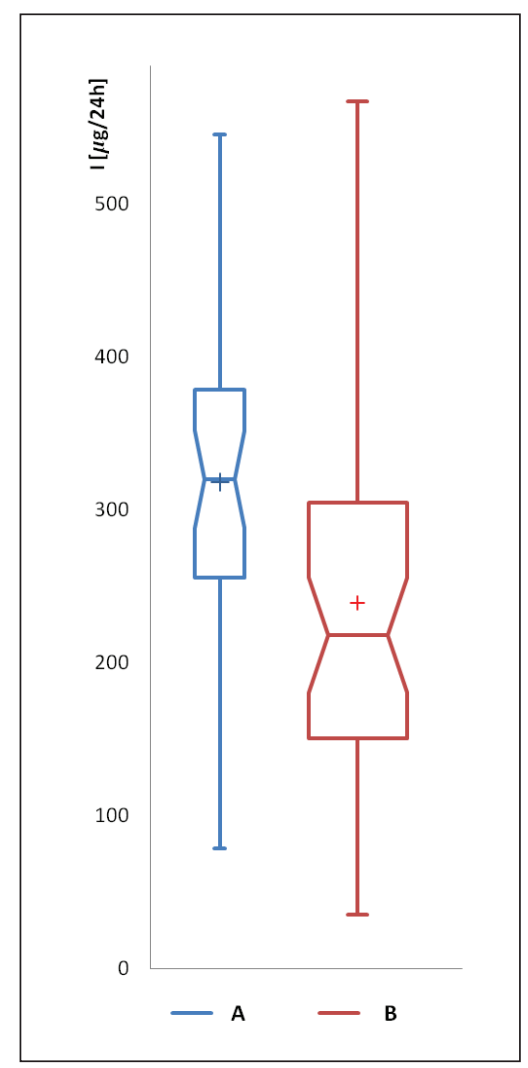

Figure 3. The 24-h iodine excretion in pregnant women. A - Subjects with multivitamin preparations; B - Subjects without multivitamin preparations 
Little research has been done in the world in the potential side effects following-up of salt iodization. Economically well developed countries, with long term iodine prophylaxis, have been facing the "epidemy" of autoimmune thyropaties (AIT) and primary hypothyroidism. In Slovakia, this problem has been well known since eighties (Podoba jr 1992). But, is the increasing prevalence of AIT caused by preventive programs? Iodine excess is generally considered to be one of the causative factors of thyroid autoimmunity. But where is the boundary line for harmful iodine excess? Where is the boundary line between the favorable and unfavorable effects of prophylactic iodized salt programs? These questions were not answered sufficiently till now. The generally used evasive answer is as follows: benefits of iodine prophylaxis far outweighed the possible side effects. An increased incidence of hypothyroidism may be the price we have to pay for preventing IDD. Some studies have supported this opinion (Teng et al. 2006; Pedersen et al. 2007; Camargo et al. 2008), but other have not (Szabolcs et al. 1997). Data are urgently needed to determine what outcomes can safely be tolerated under IDD prevention programs.

These important questions have revealed a great mistake of the Institute of Experimental Endocrinology past management not to continue in the research of IDD and its prophylaxis. This institution possessed optimal personal, mental, and technical possibilities for monitoring prophylactic program, for evaluating its benefits, and to study the changing epidemiology of thyropathies under the condition of iodine prophylaxis. This research could answered the above mentioned questions and determined the optimal iodine intake to balance benefits and risks of prophylactic program. Europe is highly fragmented with respect to IDD prevention and monitoring programs, and Slovakia could served as an example of a country, where the major problems of IDD prevention were resolved. Thus, the life's work of Julian Podoba remained uncompleted.

\section{Conclusions}

1/ Iodine nutrition in Slovakia is generally sufficient, even oversteps the requirement, with the exception of pregnant women. Iodine intake in pregnant women should be fortified by iodine containing multivitamin preparations. $2 / \mathrm{We}$ recommend to include the examination of urinary iodine into the screening of thyropathies in early pregnancy. 3 / It is not enough to implement the iodine deficiency-related disorders prevention programs, it is also necessary to stabilize such programs over time and balance the benefits with possible side effects of this program. This is the challenge for future generations of volunteers....

\section{References}

Bath SC, Steer CD, Golding J, Emmett P, Rayman MP. Effect of inadequate iodine status in UK pregnant women on cognitive outcomes in their children: results from the Avon Longitudinal Studyof Parents and Children (ALSPAC). Lancet 382, 331-7, 2013.

Camargo RYA, Tomimori ET, Neves SC, Rubio IGS, Galrao AL, Knobel M, Medeiros-Neto G. Thyroid and the environment: exposure to excessive nutritional iodine increases the prevalence of thyroid disorders in Sao Paulo, Brazil. Eur J Endocrinol 159, 293-299, 2008.

Delange F, Benker G, Caron Ph, Eber O, Ott W, Peter F, Podoba J, Simescu M, Szybinski Z, Vertongen F, Vitti P, Wiersinga W, Zamrazil V. Thyroid volume and urinary iodine in European schoolchildren: standardization of values for assessment of iodine deficiency. Eur. J. Endocrinol 136, 180-187, 1997.

Ermans AM. Etiopathogenesis of Endemic Goiter. In: Endemic Goiter and Endemic Cretinism (Eds: Stanbury JB, Hetzel BS), pp 287-301, J Wiley, New York, 1980.

Hynes KL, Otahal P, Hay I, Burgess JR. Mild Iodine Deficiency During Pregnancy Is Associated With Reduced Educational Outcomes in the Offspring: 9-Year Follow-up of the Gestational Iodine Cohort. J Clin Endocrinol Metab 98, 1954-1962, 2013.

Morreale de Escobar G, Obregon MJ, Escobar del Rey F. Role of thyroid hormone during early brain development. Eur J Endocrinol 151 (Suppl 3), U25-37, 2004.

Pearce EN, Andersson M, Zimmermann MB. Global Iodine Nutrition: Where Do We Stand in 2013? Thyroid 23, 523-528, 2013

Pedersen IB, Laurberg P, Knudsen N, Jorgensen T, Perrild H, OvesenL. An increased incidence of overt hypothyroidisim after iodine fortification of salt in Denmark: a prospective population study. J Clin Endocrinol Metab 92, 3122-7, 2007. 
Podoba J. Endemic goiter in Slovakia. Veda, Bratislava, 1962.

Podoba J, Stukovsky R. Thyroid Function after Stopping of Iodinated Salt Distribution. Acta Endocrinol Panam 3, 135-145, 1972.

Podoba J, Reisenauer R. Wirksamkeit der Jodprophylaxe in der CSSR. In: Schilddruse 1981 (Eds: Scriba PC, Rudorff KH, Weinheimer B), pp. 239-247, Thieme Verlag, Stuttgart, 1982.

Podoba J jr, Hnilica P, Srbecky M, Bednar J. Thyroid volume, goitre and diffuse lymphoid thyroiditis in adolescents after long-term iodine prophylaxis in Slovakia. J Endocrinol Invest 15, Suppl. 5, p.14, 1992

Podoba J jr, Hnilica P, Srbecky M, Podobova M. [The effectiveness of iodine prophylaxis of endemic goiter in Slovakia from the viewpoint of physical and ultrasonographic examinations of the thyroid gland]. Bratisl Lek Listy 96, 622-626, 1995.

Stagnaro-Green A, Abalovich M, Alexander E, Azizi F, Mestman J ,Negro R, Nixon A, Pearce EN, Soldin O, Sullivan S, Wiersinga W. Guidelines of the American Thyroid Association for the Diagnosis and Management of Thyroid Disease During Pregnancy and Postpartum. The American Thyroid Association Taskforce on Thyroid Disease During Pregnancy and Postpartum. Thyroid 21, 1081-1125, 2011.

Szabolcs I, Podoba J, Feldkamp J, Dohan O, Farkas I, Sajgo M, Takats KI, Goth M, Kovacs L, Kressinszki K, Hnilica $\mathrm{P}$ and Szilagyi G. Comparative screening for thyroid disorders in old age in areas of iodine deficiency, longterm iodine prophylaxis and abundant iodine intake. Clin Endocrinol 47, 87-92, 1997.

Tajtákova M, Hancinova D, Langer P, Tajtak J, Malinovsky E, Varga J. Thyroid volume of East Slovakian adolescents determined by ultrasound 40 years after the introduction of iodized salt. Klin Wochenschr 66, 749-51, 1988

Tajtakova M, Hancinova D, Tajtak J, Malinovsky E, Varga J, Langer P. Goiter prevalence and thyroid volume by ultrasonographic volumetry in two groups of schoolchildren and adolescents from east Slovakia. Endocrinol Exp 23, 85-96, 1989.

Teng W, Shan Z, Teng X, Guan H, Li Y, Teng D, Jin Y, Yu X, Fan C, Li C. Effect of iodine intake on thyroid disease in China. N Engl J Med 354, 2783-973, 2006.

WHO. Assessment of iodine deficiency disorders and monitoring their elimination. 3rd ed., WHO, Geneva, 2007.

Zimmermann M, Delenge F. Iodine supplementation of pregnant women in Europe: a review and recommendations. Eur J Clin Nutrition 58, 979-984, 2004. 